University of Wollongong

Research Online

Faculty of Engineering and Information

Faculty of Engineering and Information

Sciences - Papers: Part A

Sciences

$1-1-2017$

Design of geopolymer concrete with GGBFS at ambient curing condition using Taguchi method

Muhammad N. S Hadi

University of Wollongong, mhadi@uow.edu.au

Nabeel Farhan

University of Wollongong, naf010@uowmail.edu.au

M Neaz Sheikh

University of Wollongong, msheikh@uow.edu.au

Follow this and additional works at: https://ro.uow.edu.au/eispapers

Part of the Engineering Commons, and the Science and Technology Studies Commons

Research Online is the open access institutional repository for the University of Wollongong. For further information contact the UOW Library: research-pubs@uow.edu.au 


\title{
Design of geopolymer concrete with GGBFS at ambient curing condition using Taguchi method
}

\author{
Abstract \\ In this paper, the Taguchi method has been used to design optimum mix proportions for geopolymer \\ concrete with ground granulated blast furnace slag (GGBFS) as aluminosilicate source at ambient curing \\ condition. The influences of binder content, alkaline activator to binder content (Al/Bi) ratio, sodium \\ silicate to sodium hydroxide (SS/SH) ratio, and sodium hydroxide (SH) concentration on the geopolymer \\ concrete were investigated. A total of nine mix designs were evaluated. It was found that specimens with \\ a binder content of $450 \mathrm{~kg} / \mathrm{m}^{3}, \mathrm{Al} / \mathrm{Bi}$ ratio of $0.35, \mathrm{SS} / \mathrm{SH}$ ratio of 2.5 , and $\mathrm{SH}$ concentration of $14 \mathrm{M}$ \\ produced the highest 7-day compressive strength (60.4 MPa). However, the setting time was found to be \\ short. Hence, fly ash (FA), metakaolin (MK), and silica fume (SF) were used as partial replacement of \\ GGBFS in different proportions to increase the setting time. It was found that the setting time improved \\ for the partial replacement of GGBFS with FA, MK, and SF.

\section{Keywords} \\ method, condition, design, geopolymer, concrete, ggbfs, ambient, taguchi, curing \\ Disciplines \\ Engineering | Science and Technology Studies

\section{Publication Details} \\ Hadi, M. N. S., Farhan, N. A. \& Sheikh, M. Neaz. (2017). Design of geopolymer concrete with GGBFS at \\ ambient curing condition using Taguchi method. Construction and Building Materials, 140 424-431.
}


4

29

30

\title{
Design of Geopolymer Concrete with GGBFS at Ambient Curing Condition Using Taguchi Method
}

\author{
Muhammad N.S. Hadi ${ }^{1 *}$, Nabeel A. Farhan ${ }^{2}$, M. Neaz Sheikh ${ }^{3}$ \\ ${ }^{1 *}$ Associate Professor, School of Civil, Mining and Environmental Engineering, University of \\ Wollongong, Australia \\ ${ }^{2}$ Ph.D. Candidate, School of Civil, Mining and Environmental Engineering, University of \\ Wollongong, Australia \\ ${ }^{3}$ Associate Professor, School of Civil, Mining and Environmental Engineering, University of \\ Wollongong, Australia
}

9 Correspondence:

0 Muhammad N. S. Hadi

1 School of Civil, Mining \& Environmental Engineering

2 University of Wollongong, Australia

3 E-mail: mhadi@uow.edu.au

24 Telephone: + 61242214762

25 Facsimiles: + 61242213238 


\section{Design of Geopolymer Concrete with GGBFS at Ambient Curing} Condition Using Taguchi Method

\section{Abstract}

In this paper, the Taguchi method has been used to design optimum mix proportions for geopolymer concrete with ground granulated blast furnace slag (GGBFS) as aluminosilicate source at ambient curing condition. The influences of binder content, alkaline activator to binder content $(\mathrm{Al} / \mathrm{Bi})$ ratio, sodium silicate to sodium hydroxide $(\mathrm{SS} / \mathrm{SH})$ ratio, and sodium hydroxide $(\mathrm{SH})$ concentration on the geopolymer concrete were investigated. A total of nine mix designs were evaluated. It was found that specimens with a binder content of $450 \mathrm{~kg} / \mathrm{m}^{3}$, $\mathrm{Al} / \mathrm{Bi}$ ratio of $0.35, \mathrm{SS} / \mathrm{SH}$ ratio of 2.5 , and $\mathrm{SH}$ concentration of $14 \mathrm{M}$ produced the highest 7day compressive strength $(60.4 \mathrm{MPa})$. However, the setting time was found to be short. Hence, fly ash (FA), metakaolin (MK), and silica fume (SF) were used as partial replacement of GGBFS in different proportions to increase the setting time. It was found that the setting time improved for the partial replacement of GGBFS with FA, MK, and SF.

Keywords: Geopolymer, Taguchi method, Compressive strength, Setting time 


\section{Highlights}

57 - Geopolymer concrete with GGBFS has been produced at ambient curing condition

58 - GGBFS improved early strength development of geopolymer concrete

59 - Compressive strength reduced for partial replacement of GGBFS with FA, MK, and

60 $\mathrm{SF}$

61

- Setting time increased for partial replacement of GGBFS with FA, MK, and SF

62

- Workability increased for partial replacement of GGBFS with FA, MK, and SF

63

64

65

66

67

68

69

70

71

72

73

74

75

76

77 


\section{Introduction}

79 Climate change due to global warming is a critical environmental issue having considerable negative impacts on all living organisms in this world. Global warming is caused by greenhouse gas emissions including the emission of methane, nitrous oxide, and carbon dioxide into the atmosphere. It was reported that globally the production of cement contributed to about 5 to $7 \%$ of total carbon dioxide $\left(\mathrm{CO}_{2}\right)$ emission into the atmosphere [1].

In 2013, the production of cement in Australia contributed to the emission of 36 billion tonnes of $\mathrm{CO}_{2}$ [2]. It is estimated that the production of one tonne of Ordinary Portland Cement (OPC) releases about one tonne of $\mathrm{CO}_{2}$ into the atmosphere [3, 4]. The consumption of cement in the world for 2014 was 3.7 billion metric tonnes [5]. Considering an annual growth of $4 \%$, the consumption of cement by 2020 will be 4.7 billion metric tonnes. Hence, the development of green concrete without OPC has become important. Research investigations on geopolymer concrete $[6,7]$ and alkali activated concrete [8-11] as an alternative for OPC concrete started a few decades ago and have recently gained popularity as construction materials. This paper deals only with geopolymer concrete.

Geopolymer concrete does not contain any OPC and hence it is considered as green concrete. Geopolymer concrete is proven to have good mechanical properties with reduced greenhouse gas emissions [5]. It not only reduces the carbon footprint compared to OPC but also uses a large amount of industrial waste material such as slag, fly ash, and silica fume [5].

97 There are two main components in geopolymer concrete: an alkaline activator and the source of aluminosilicate materials. The most common alkaline activator is a combination of sodium silicate and sodium hydroxide. However, potassium silicate and potassium hydroxide can also be used. The alkaline activator plays an important role in the polymerization process 
[12]. The source materials of the binder used in geopolymer concrete depend on the source of the aluminosilicate. These aluminosilicate materials must be rich in aluminate ( $\mathrm{Al}$ ) and silicate $(\mathrm{Si})$. These aluminosilicate materials can be a by-product material such as slag [13], fly ash [14-16], and silica fume [17]. In addition, the aluminosilicate can be obtained from natural sources including clay and metakaolin [18]. The choice of source material for the production of geopolymer concrete depends on several factors including cost, availability, and application [19].

Most of the previous studies use heat to cure geopolymer concrete; as such its use is limited to precast concrete members. Geopolymer concrete in ambient curing condition will have wider applications in situ construction as well as in precast construction. Ambient curing conditions will reduce the energy and cost associated with the heat curing process.

The setting time, workability, and compressive strength of geopolymer concrete and paste were investigated in the available literature. Rao and Rao [20] investigated the final setting time and compressive strength of geopolymer mortar. The main aluminosilicate source material (Class F) fly ash was partially replaced with a ground-granulated blast furnace slag, and the alkaline activator was a mixture of sodium silicate with sodium hydroxide solution. It was found that the final setting time was significantly reduced when the fly ash was replaced by GGBFS. In another study, Lee and Lee [21] investigated the setting time and mechanical properties of alkali-activated fly ash/slag concrete manufactured at room temperature. The test results showed that the setting times of the alkali-activated fly ash/slag paste decreased as the amount of slag and the concentration of the SH solution increased. Nath and Sarker [22] investigated the workability and compressive strength of fly ash-based geopolymer concrete. 
based geopolymer concrete was increased when GGBFS was used as a small proportion of the binder.

126 A large number of studies were conducted on geopolymer concrete, but there is still no consensus on the influence of different parameters on the properties (e.g., compressive strength and workability) of geopolymer concrete. The main parameters which influence the properties of geopolymer concrete include aluminosilicate source, curing conditions, type of alkaline activator, combination and concentration of the activator, and the alkaline activator to binder ratio [23]. It might be difficult to investigate the influence of all the parameters in a single investigation. However, through a well-designed experimental program, the parameters which influence the proportion of geopolymer concrete can be adequately investigated [23]. The well-known Taguchi method [24] can be used for this purpose. The Taguchi method is a fractional factorial design method which uses a special set of arrays called orthogonal arrays (OA) for the design of experiments to investigate a large number of variables with a small number of experiments. The design of experiments using OA is quite efficient compared to traditional experiment design methods [25]. The OA reduce the number of experiments and minimize uncontrollable parameters [25]. For instance, when using four parameters at three proportions, the traditional factorial design needs $3^{4}$ or 81 test runs, while the Taguchi method requires only 9 test runs. The Taguchi method uses a signal-to-noise $(\mathrm{S} / \mathrm{N})$ ratio for optimization. The $\mathrm{S} / \mathrm{N}$ ratio helps in data analysis and prediction of optimum result. In effect, OA provides a set of well-balanced experiments and $\mathrm{S} / \mathrm{N}$ ratio serves as objective function for optimization. The main advantages of the Taguchi methods are the efficiency, cost effectiveness, robustness, and ease of interpretation of the output.

The Taguchi method has been widely used in other engineering applications, but the application of the Taguchi method to geopolymer concrete is very limited [26-28]. Riahi et al. 
148 [26] investigated the 2- and 7-day compressive strength of fly ash-based geopolymer concrete 149 designed using the Taguchi method. They investigated the effects of SH concentration and 150 curing condition on the compressive strength using the Taguchi method. Olivia et al. [27] 151 designed nine geopolymer concrete mixes by considering the effects of aggregate content, 152 sodium silicate to sodium hydroxide ratio, alkaline activator to fly ash ratio, and curing method. It was reported that the Taguchi method could be used to optimize the components of the geopolymer concrete mix. Khalaj et al. [28] found that split tensile strength of Portland cement-based geopolymers could be suitably designed using the Taguchi method.

156

The aim of this study is to propose an optimum mix proportion for geopolymer concrete by considering most influencing parameters resulting in high compressive strength and desirable workability at ambient curing condition by using the Taguchi method. The aim of the paper is achieved through extensive experimental investigations. The development of a mathematical model taking into account all the influential parameters is considered beyond the scope of the paper.

\section{Experimental details}

\subsection{Materials}

The materials used for geopolymer concrete in this study were ground granulated blast furnace slag (GGBFS), silica fume (SF), fly ash (FA), and metakaolin (MK). The GGBFS and SF were supplied by the Australian (Iron \& Steel) Slag Association [29]. The FA classified as class F according to ASTM C618-08 [30], which was supplied by Eraring Power Station Australia [31]. The MK was supplied by Calix Australia [32]. The chemical compositions of GGBS, FA, and MK have been shown in Table 1. 
Coarse aggregate with a maximum aggregate size of $10 \mathrm{~mm}$ and the river sand as the fine aggregate were used in this study. Sodium silicate solution blended with sodium hydroxide was used as an alkaline activator. Caustic soda $(\mathrm{NaOH})$ was dissolved in potable water to produce sodium hydroxide solution with different concentrations. Sodium silicate solution $\left(\mathrm{Na}_{2} \mathrm{SiO}_{3}\right)$ (Grade D) was supplied by PQ Australia [33]. The dry density of the sodium silicate solution was $1.53 \mathrm{~g} / \mathrm{cm}^{3}$. The sodium silicate solution $\left(\mathrm{Na}_{2} \mathrm{SiO}_{3}\right)$ includes $14.7 \%$ sodium oxide, $29.4 \%$ silicate and $44.1 \%$ solids. High range water reducers (commercially available Glenium 8700) supplied by BASF Australia [34] were used to improve the workability of the geopolymer concrete.

\subsection{Optimum mix design of geopolymer concrete}

In this study, the Taguchi method [24] was used to explore the optimal mix design of geopolymer concrete in order to maximize the compressive strength at ambient curing condition. The Taguchi experimental design was performed by Qualitek-4 [35]. The main aim was to determine the optimal mix design to produce high strength geopolymer concrete considering the parameters that influence the compressive strength.

Four main parameters, including binder contents $\left(400,450\right.$, and $\left.500 \mathrm{~kg} / \mathrm{m}^{3}\right), \mathrm{Al} / \mathrm{Bi}$ ratio $(0.35$, 0.45 , and 0.55$)$, SS/SH $(1.5,2$, and 2.5), and SH concentration (10, 12, and $14 \mathrm{M})$ were considered in the mix design (Table 2). A total of 9 trial mixes were prepared depending on L9 array obtained using the Taguchi method [24]. The component parameters are given for each trial mix (TM1-TM9) in Tables 3 and 4. The ratio of $\mathrm{H}_{2} \mathrm{O} / \mathrm{Na}_{2} \mathrm{O}$ was kept constant at 12.5 in order to obtain geopolymer concrete with good workability [12]. The compressive strengths obtained from the trial mixes of geopolymer concrete were used in calculating the response index for each trial mix based on the signal-to- noise $(\mathrm{S} / \mathrm{N})$ ratio [36]. The response 
index for each parameter was determined by taking the average of the 7-day compressive strengths for the trial mixes which included the considered parameter. For example, parameter $\mathrm{Al} / \mathrm{Bi}$ ratio of 0.35 was tested in three trials mixes: TM1, TM4, and TM7 (Table 3). The compressive strength of trial mixes TM1, TM4, and TM7 was 40.89, 56.05, and 52.23, respectively (Table 5). The response index for trial mixes TM1, TM4, and TM7 was equal to $((40.89+56.05+52.23) / 3=49.72)$, which was greater than the response index for $\mathrm{Al} / \mathrm{Bi}$ ratio of 0.45 and 0.55 (Fig. 3). Hence, the optimum $\mathrm{Al} / \mathrm{Bi}$ ratio was 0.35 . Finally, the results were evaluated by analyses of variable (ANOVA) to determine the optimum proportion, based on $\mathrm{S} / \mathrm{N}$ ratio, of each parameter.

\subsection{Specimens preparation and testing}

Geopolymer concrete specimens were prepared by mixing the dry material (slag, coarse aggregate, and sand) in a pan mixer. Afterwards, alkaline activators (SS/SH) were added to the dry mix. Finally, water and superplasticizer were added. The procedure of the mixing geopolymer concrete implemented in this study was similar to that adopted in Rangan [3]. It should be noted that the mixing procedure may affect the compressive strength and workability of the geopolymer concrete. The dry materials were mixed for about 1 minute and then half of the amount of alkaline activator was added into the pan and mixed for about 2 minutes. The remaining amount of alkaline activator with water and superplasticizer were poured into the pan mixer and mixed for approximately 2 minutes until the mixture became well combined and homogeneous.

In this study, polyvinyl chloride (PVC) moulds of $200 \mathrm{~mm}$ length and $100 \mathrm{~mm}$ diameter (200 $\mathrm{x} 100 \mathrm{~mm}$ ) were used for casting concrete to measure the compressive strength. The specimens were cast in three layers of geopolymer concrete and each layer was vibrated for 
10 seconds. The specimens were left in the laboratory at an ambient condition for 24 hours.

217 The specimens were then removed from the moulds and left in an ambient condition.

218 The compressive strength was measured according to Australian Standard (AS 1012.9-1999)

219 [37] using W\&T 1800 testing machine. The tests were carried out on three specimens for

220 each mix on the $7^{\text {th }}$ and the $28^{\text {th }}$ day and average strengths are reported in Table 5.

221 The setting time of the geopolymer concrete was evaluated by partially replacing GGBFS

222 with different proportions of FA, MK, and SF. The initial and final setting times reported in 223 this study are the initial and final setting times of geopolymer paste without the coarse and

224 fine aggregate. The initial setting time was measured from the start of the mixing to the time when the needle penetrates to a point $5 \mathrm{~mm}$ from the bottom of the base plate mould. The final setting time was measured from the start of the mixing to the time when the needle only

227 makes an impression on the past surface.

228 The setting time of the geopolymer concrete was obtained by penetration resistance measurements according to ASTM C 191-08 [38]. Setting time tests were conducted under an ambient temperature of $25 \pm 2^{\circ} \mathrm{C}$. The workability of fresh geopolymer concrete was measured by slump tests according to AS 1012.3.1[39]. The slump tests were conducted immediately

232 after mixing at ambient conditions.

\section{$233 \quad 3 . \quad$ Results and discussion}

\section{3.1. Optimum components for geopolymer concrete with GGBFS}

235 Compressive strength was used as the evaluation criterion for the 9 trial mixes (TM1-TM9)

236 according to the Taguchi method, as shown in Fig. 1. The highest compressive strength was

237 obtained by TM4 specimens with a binder content of $450 \mathrm{~kg} / \mathrm{m}^{3}, \mathrm{Al} / \mathrm{Bi}$ ratio $0.35, \mathrm{SS} / \mathrm{SH}$ ratio 
of 2, and SH concentration of $14 \mathrm{M}$. The lowest compressive strength was obtained by TM9 specimens with a binder content of $500 \mathrm{~kg} / \mathrm{m}^{3}, \mathrm{Al} / \mathrm{Bi}$ ratio $0.55, \mathrm{SS} / \mathrm{SH}$ ratio of 2 , and $\mathrm{SH}$ concentration of $10 \mathrm{M}$. It is noted that $\mathrm{SS} / \mathrm{SH}$ ratio for both mixes was 2 .

The main differences between TM4 and TM9 is the binder content, $\mathrm{Al} / \mathrm{Bi}$ ratio, and $\mathrm{SH}$ concentration. The effect of SH concentration on the compressive strength of the geopolymer concrete has not been completely agreed on by the researchers. Some of the studies showed that the high concentration of SH led to an increased compressive strength [40], but some other studies showed increase in the SH concentration led to lower compressive strength [41]. It can be seen in Fig. 2 that the compressive strength of the geopolymer concrete increased with increases in the $\mathrm{SH}$ concentration. It appears that there is a strong relationship between the aluminosilicate sources and $\mathrm{SH}$ concentration. The increase in the $\mathrm{SH}$ concentration dissolves the initial solid more and consequently increases geopolymerization reaction, which helps in achieving higher compressive strength [42]. It is considered that for geopolymer with GGBFS as the aluminosilicate source, $\mathrm{SH}$ concentration of $14 \mathrm{M}$ might have the best effect on increasing the strength.

The compressive strength of the geopolymer concrete is also significantly influenced by $\mathrm{Al} / \mathrm{Bi}$ ratio. In this study, specimens TM1, TM4, and TM7 achieved 7-day compressive strengths of $40.89,56.05$, and $52.23 \mathrm{MPa}$, respectively. These high compressive strengths showed that one of the main parameters affecting the geopolymer specimens is $\mathrm{Al} / \mathrm{Bi}$ ratio. The increase in the Al/Bi ratio resulted in a decrease in compressive strength. The reason for this decrease in compressive strength can be attributed to the higher $\mathrm{AL} / \mathrm{Bi}$ ratio of the mixture. Excess alkaline activator caused an increase in the amount of water in the mixture which hindered geopolymerization [43]. 
261 In particular, an increase in the $\mathrm{Al} / \mathrm{Bi}$ ratio from 0.35 (TM4) to 0.55 (TM3) with the same $\mathrm{SH}$ concentration $(14 \mathrm{M})$ resulted in a significant reduction in the 7-day compressive strength from 56.05 MPa (TM4) to 36.94 MPa (TM3) (Table 5). Based on the results obtained in this study it can be concluded that the influence of $\mathrm{Al} / \mathrm{Bi}$ ratio on the compressive strength gain was significant. This is clearly demonstrated by the fact that for the same Al/Bi ratio, the compressive strength varied, depending primarily on the alkaline activator concentration as well as on the blend of binder.

One of the other parameters affecting the strength of geopolymer is binder content. Based on the test results obtained, it can be observed from Fig. 2 that with the increase in the binder content from $400 \mathrm{~kg} / \mathrm{m}^{3}$ to $450 \mathrm{~kg} / \mathrm{m}^{3}$, the compressive strength of the geopolymer concrete increased. However, the compressive strength decreased with the increase in the binder content beyond $450 \mathrm{~kg} / \mathrm{m}^{3}$.

Based on the above discussion, it is difficult to ascertain the optimum proportions for each considered parameter. Factorial analysis was conducted using Qualitek-4 [35] to investigate the effects of each parameter on the compressive strength of the geopolymer concrete. Factorial diagrams and the significance of the main parameters that affect the compressive strength have been shown in Figure 2 and Figure 3, respectively. The percentage of participation of each parameter and the optimum level of the considered parameters on the compressive strength is shown in Table 6.

Fig. 3 and Table 6 show that the Al/Bi ratio is the most significant parameter that influences the geopolymer concrete with a percentage of participation of $71.23 \%$ and $\mathrm{Al} / \mathrm{Bi}$ of 0.35 as the optimum level. This indicates that the lower ratio of $\mathrm{Al} / \mathrm{Bi}$ could produce higher compressive strength of geopolymer concrete (Fig. 2). 
284 It can also be observed that the second influential parameter is the SH concentration with a percentage of participation of $11.66 \%$. Table 6 shows that the $\mathrm{SH}$ concentration of $14 \mathrm{M}$ is the optimum level. This indicates that a high concentration of $\mathrm{SH}$ produces high compressive strength of geopolymer concrete (Fig. 2).

The third influential parameter is the binder content with a percentage of participation of $10.09 \%$. Table 6 shows that the binder content of $450 \mathrm{~kg} / \mathrm{m}^{3}$ is the optimum level, which indicates that binder content of $450 \mathrm{~kg} / \mathrm{m}^{3}$ produces high compressive strength of geopolymer concrete (Fig. 2). The SS/SH ratio has the lowest percentage of participation of $7.10 \%$. Table 6 illustrates that SS/SH ratio of 2.5 is the optimum level. This indicates that a high ratio of SS/SH could produces high compressive strength of geopolymer concrete (Fig. 2).

Finally, TM10 mix was prepared and tested according to the optimum levels presented in concentration of $14 \mathrm{M}$. The average of compressive strength of the TM10 was $60.4 \mathrm{MPa}$ on the $7^{\text {th }}$ day, which was greater than the compressive strengths obtained from the nine previous trial mixes (TM1-TM9). However, the setting time was found to be short. The initial and final setting times of the TM10 specimens were 25 minutes and 55 minutes, respectively. Such fast setting time behaviour may not be convenient for geopolymer concrete in conventional construction. Hence, FA, MK, and SF were used as partial replacements of GGBFS in different proportions to increase the setting time. 
Fig. 4 shows the setting time of the specimens by partially replacing GGBFS in TM10 with different proportion of FA, MK, and SF. Replacement of GGBFS with FA, MK, and SF ranged from $10 \%$ to $60 \%$.

The initial setting time of the different mixes considered in this investigation varied from 25 to 75 minutes and the final setting time varied from 55 to 105 minutes. It was found that increase in the partial replacement of GGBFS with FA, MK, and SF resulted in increased initial and final setting times. When $60 \%$ of GGBFS were replaced with FA, the initial setting time increased from 25 minutes to 75 minutes and the final setting time increased from 55 minutes to 105 minutes. It was also observed that by replacing $60 \%$ of GGBFS with MK, the initial setting time increased from 25 minutes to 55 minutes and the final setting time increased from 55 minutes to 90 minutes. Finally, replacing $60 \%$ of GGBFS with SF, the initial setting time increased from 25 minutes to 70 minutes and the final setting time increased from 55 minutes to 100 minutes. From the test data, it can be seen that the GGBFS quickly reacts with alkaline activator compared to FA, MK, and SF. Thus, the setting time of geopolymer paste with GGBFS is shorter than the setting time with other pozzolanic materials. The reason for the short setting time can be attributed to the higher calcium content present in GGBFS (Table 1). The presence of high calcium content in GGBFS results in an increase in the reactivity of the geopolymer by forming an amorphously structured $\mathrm{Ca}-\mathrm{Al}-\mathrm{Si}$ gel. From the test data, it can be observed that the setting time has significantly increased when the GGBFS is partially replaced by FA, MK, and SF.

Fig. 5. shows the effect of partial replacement of GGBFS with different proportion of FA, MK, and SF on workability. The results were compared with the control geopolymer mixture TM10. It can be observed from Figure 5 that the slump of geopolymer concrete was influenced by the inclusion of FA, MK, and SF in the binder. The control geopolymer 
mixture TM10, which contains $100 \%$ GGBFS, showed the lowest slump. The slump increased with the increase of FA, MK, and SF in the mixture. The effect was more significant at a higher ratio of FA, MK, and SF content. The trend was almost similar for all replacement ratios but more significant with $60 \%$ FA and SF. The reason for the increased slump of the mixtures is most likely due to the increased mobility of spherical shaped FA and SF in contrast to irregular shaped slag particles.

Thus, it can be concluded that to have a required value of setting time and workability a convenient combination of GGBFS and FA can be a promising option of geopolymer concrete.

\subsection{Effect of FA, MK, and SF on the compressive strength of geopolymer concrete with GGBFS}

The compressive strength of geopolymer concrete with different proportions of FA, MK, and SF as partial replacement of GGBFS is shown in Table 8 and Fig. 6. It was found that the compressive strength of geopolymer concrete decreased for partial replacement of GGBFS with FA, MK, and SF under ambient curing conditions. The geopolymer concrete with GGBFS has been shown to achieve a compressive strength of $60.4 \mathrm{MPa}$ on the $7^{\text {th }}$ day.

For a replacement of $60 \%$ GGBFS with FA, $41 \%$ decrease in the compressive strength of the geopolymer concrete was observed. In addition, by replacing $60 \%$ GGBFS with MK and SF, the decreases in compressive strength of geopolymer concrete were $58 \%$ and $52 \%$, respectively. The reason for the decrease in compressive strength can be attributed to the decrease in the intensity of the calcium content when the amount of GGBFS was decreased in the mix. The decrease in calcium content in the mix results in a delay in the polymerization reaction and the formation of an amorphously structured Ca-Al-Si gel was hindered. Hence, 
slag based geopolymer modified with FA can be considered as a suitable binder for geopolymer concrete under ambient curing conditions for reasonably high compressive strength and adequate setting time.

\section{Conclusion}

Based on the experimental program presented in this study, following conclusions can be drawn:

1. The geopolymer concrete with a binder content of $450 \mathrm{~kg} / \mathrm{m}^{3}, \mathrm{Al} / \mathrm{Bi}$ ratio of $0.35, \mathrm{SS} / \mathrm{SH}$ ratio of 2.5, and $\mathrm{SH}$ concentration of $14 \mathrm{M}$ achieved the highest 7-day compressive strength (60.4 MPa) at ambient curing conditions.

2. The inclusion of FA, MK, and SF as partial replacement of GGBFS reduces the compressive strength of geopolymer concrete.

3. Replacement of the GGBFS with FA, MK, and SF increases the initial and final setting time of the geopolymer paste and increases the slump of the fresh concrete as well.

4. To increase the setting time of geopolymer concrete under ambient curing conditions, a combination of GGBFS with FA can be a possible solution, as the blend of GGBFS with FA achieved longer setting time compared with the blend of GGBFS with MK and SF.

5. The inclusion of FA in the GGBFS-based geopolymer mixture is found to be a suitable binder of geopolymer concrete for in situ construction, in addition to the precast construction, under ambient curing conditions, thus eliminating the necessity for heat curing.

Finally, the information presented in this study will be beneficial in the design of geopolymer concrete at ambient curing conditions in order to enhance the durability of geopolymer concrete and, in particular, to enhance its mechanical properties. In addition, the data 
374 presented in this paper will also be valuable in the selection and application of appropriate 375 testing methods for the geopolymer concrete under ambient curing condition.

\section{Acknowledgements}

377 The authors would like to gratefully acknowledge the Australian (Iron \& Steel) Slag 378 Association, Wollongong, Australia for providing aluminosilicate materials required for this 379 study. The help of the technical officers of the concrete laboratory staff of Wollongong 380 University, Australia is gratefully acknowledged. The second author is grateful for the 381 financial supports received from the Iraqi government.

382

383

384

385

386

387

388

389

390

391

392 


\section{References}

1. McLellan, B. C., Williams, R. P., Lay, J., Van Riessen, A., \& Corder, G. D. (2011). Costs and carbon emissions for geopolymer pastes in comparison to ordinary Portland cement. Journal of Cleaner Production, 19(9), 1080-1090.

2. Canadell, P., \& Raupach, M. (2014). Global carbon report: emissions will hit new heights in 2014. ECOS, 2014(199).

3. Rangan BV (2008). Fly ash-based geopolymer concrete, Curtin University of Technology.

4. Wallah, S. E. (2010). Creep behaviour of fly ash-based geopolymer concrete. Civil Engineering Dimension, 12(2), 73-78.

5. Reed, M., Lokuge, W., \& Karunasena, W. (2014). Fibre-reinforced geopolymer concrete with ambient curing for in situ applications. Journal of Materials Science, 49(12), 4297-4304.

6. Temuujin, J., Williams, R. P., \& Van Riessen, A. (2009). Effect of mechanical activation of fly ash on the properties of geopolymer cured at ambient temperature. Journal of Materials Processing Technology, 209(12), 5276-5280.

7. Junaid, M. T., Kayali, O., Khennane, A., \& Black, J. (2015). A mix design procedure for low calcium alkali activated fly ash-based concretes. Construction and Building Materials, 79, 301-310.

8. Bernal, S. A., de Gutiérrez, R. M., \& Provis, J. L. (2012). Engineering and durability properties of concretes based on alkali-activated granulated blast furnace slag/metakaolin blends. Construction and Building Materials, 33, 99-108.

9. Yang, K. H., Song, J. K., Lee, K. S., \& Ashour, A. F. (2009). Flow and Compressive Strength of Alkali-Activated Mortars.ACI Materials Journal, 50-85

10. Collins, F., \& Sanjayan, J. G. (2001). Microcracking and strength development of alkali activated slag concrete. Cement and Concrete Composites, 23(4), 345-352.

11. Wardhono, A., Law, D. W. \& Molyneaux, T. C. 2015. Long-term performance of alkali activated slag concrete. Journal of Advanced Concrete Technology, 13, 187192.

12. Palomo, A., Grutzeck, M. W., \& Blanco, M. T. (1999). Alkali-activated fly ashes: cement for the future. Cement and concrete research, 29(8), 1323-1329.

13. Kumar, S., Kumar, R., \& Mehrotra, S. P. (2010). Influence of granulated blast furnace slag on the reaction, structure and properties of fly ash based geopolymer. Journal of Materials Science, 45(3), 607-615.

14. Chindaprasirt, P., Chareerat, T., \& Sirivivatnanon, V. (2007). Workability and strength of coarse high calcium fly ash geopolymer. Cement and Concrete Composites, 29(3), 224-229.

15. Somna, K., Jaturapitakkul, C., Kajitvichyanukul, P., \& Chindaprasirt, P. (2011). $\mathrm{NaOH}$-activated ground fly ash geopolymer cured at ambient temperature. Fuel, 90(6), 2118-2124.

16. Hardjito, D., Wallah, S. E., Sumajouw, D. M., \& Rangan, B. V. (2004). On the development of fly ash-based geopolymer concrete. ACI Materials Journal-American Concrete Institute, 101(6), 467-472.

17. Qing, Y., Zenan, Z., Deyu, K., \& Rongshen, C. (2007). Influence of nano-SiO 2 addition on properties of hardened cement paste as compared with silica fume. Construction and Building Materials, 21(3), 539-545.

18. Muñiz-Villarreal, M. S., Manzano-Ramírez, A., Sampieri-Bulbarela, S., Gasca-Tirado, J. R., Reyes-Araiza, J. L., Rubio-Ávalos, J. C., \& Amigó-Borrás, V. (2011). The 
effect of temperature on the geopolymerization process of a metakaolin-based geopolymer. Materials Letters, 65(6), 995-998.

19. Lloyd, N. A., \& Rangan, B. V. (2010). Geopolymer concrete with fly ash. In Second international conference on sustainable construction materials and technologies (Vol. 3, pp. 1493-1504).

20. Rao, G. M., \& Rao, T. G. (2015). Final Setting Time and Compressive Strength of Fly Ash and GGBS- Based Geopolymer Paste and Mortar. Arabian Journal for Science and Engineering, 40(11), 3067-3074.

21. Lee, N. K., \& Lee, H. K. (2013). Setting and mechanical properties of alkali-activated fly ash/slag concrete manufactured at room temperature. Construction and Building Materials, 47, 1201-1209.

22. Nath, P., \& Sarker, P. K. (2014). Effect of GGBFS on setting, workability and early strength properties of fly ash geopolymer concrete cured in ambient condition. Construction and Building Materials, 66, 163-171.

23. Nazari, A., Khanmohammadi, H., Amini, M., Hajiallahyari, H., \& Rahimi, A. (2012). Production geopolymers by Portland cement: designing the main parameters' effects on compressive strength by Taguchi method. Materials \& Design, 41, 43-49.

24. Taguchi, G., Chowdhury, S., \& Wu, Y. (2005). Taguchi's quality engineering handbook. Wiley- Interscience.

25. Türkmen, İ., Gül, R., \& Çelik, C. (2008). A Taguchi approach for investigation of some physical properties of concrete produced from mineral admixtures. Building and Environment, 43(6), 1127-1137.

26. Riahi, S., Nazari, A., Zaarei, D., Khalaj, G., Bohlooli, H., \& Kaykha, M. M. (2012). Compressive strength of ash-based geopolymers at early ages designed by Taguchi method. Materials \& Design, 37, 443-449.

27. Olivia, M., \& Nikraz, H. (2012). Properties of fly ash geopolymer concrete designed by Taguchi method. Materials \& Design, 36, 191-198.

28. Khalaj, G., Hassani, S. E. S., \& Khezrloo, A. (2014). Split tensile strength of OPCbased geopolymers: Application of DOE method in evaluating the effect of production parameters and their optimum condition. Ceramics International, 40(7), 10945-10952.

29. Australasian Slag Association (2016). Australasian Slag Association, Wollongong, NSW 2500, accessed on January 2016, < http://www.asa-inc.org.au/groundgranulated-blast-furnace-slag.php>.

30. ASTM, C. 618 Standard Specification for Coal Fly Ash and Raw or Calcined Natural Pozzolan for use as a Mineral Admixture in Portland Cement Concrete. American Society for Testing of Materials, Philadelphia, USA

31. Eraring Australia (2016). Eraring power station Australia, Level 16, 227 Elizabeth Street Sydney NSW 2000, accessed on Janoury 2016, $<$ https://www.originenergy.com.au/about/who-we-are/what-we-do/generation.html>.

32. Calix Australia (2016). Calix Limited, 1/9-11 Bridge St, Pymble NSW 2073, accessed on January 2016, <http://www.calix.com.au/index.php>.

33. PQ Australia (2016). PQ Australia Limited, 8/10 Riverside Rd, Chipping Norton NSW 2170, accessed on January 2016, <http://www.pqcorp.com/>.

34. BASF Ausrtalia (2016). BASF Australia Limited, 521 Kororoit Creek Rd, Altona VIC 3018, accessed on January 2016, <www.basf.com.au/>.

35. Ranjit K. Roy (1996). Qualitek-4 Software for Automatic Design of Experiment Using Taguchi Approach, IBM or Compatible computer, Nutek, Inc. < http://Nutekus.com/wp-q4w.html>. 
36. Ross, P. J. (1996). Taguchi techniques for quality engineering loss function, orthogonal experiments. Parameter and Tolerance Design.

37. AS 1012.9. (1999). Methods of testing concrete-determination of compressive strength of concrete specimens. Sydney: Standards Australia Limited.

38. ASTM C-191-08. (1995). Standard test methods for the time of setting of hydraulic cement by Vicat needle. West Conshohocken.

39. AS 1012.3.1-1998. Methods of testing concrete - method 9: determination of properties related to the consistency of concrete - slump test. Standards Australia; 1998.

40. Wongpa, J., Kiattikomol, K., Jaturapitakkul, C., \& Chindaprasirt, P. (2010). Compressive strength, modulus of elasticity, and water permeability of inorganic polymer concrete. Materials \& Design, 31(10), 4748-4754.

41. Nazari, A., Bagheri, A., \& Riahi, S. (2011). Properties of geopolymer with seeded fly ash and rice husk bark ash. Materials Science and Engineering: A, 528(24), 73957401.

42. Temuujin, J., Williams, R. P., \& Van Riessen, A. (2009). Effect of mechanical activation of fly ash on the properties of geopolymer cured at ambient temperature. Journal of Materials Processing Technology, 209(12), 5276-5280.

43. Ruiz-Santaquiteria, C., Skibsted, J., Fernández-Jiménez, A., \& Palomo, A. (2012). Alkaline solution/binder ratio as a determining factor in the alkaline activation of aluminosilicates. Cement and Concrete Research, 42(9), 1242-1251.

2

4

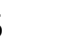


529 List of Tables

530 Table 1 Chemical composition (mass \%) for GGBS, FA, SF, and MK.

531 Table 2 Parameters and proportions used in Taguchi experiment design.

532 Table 3 Parameters and values used in geopolymer concrete trial mixes.

533 Table 4 Mix proportions of trial mixes.

534 Table 5 Compressive strength of trial mixes of geopolymer concrete under ambient curing 535 condition.

536

537

538

539

540

541

542

543

544

545

546

547

548

549

550

551

552

553
Table 6 Percentage of participation and Optimum levels of the considered parameters on the 7-day compressive strength.

Table 8 Changes in the compressive strength of geopolymer concrete for the partial replacement of GGBFS with FA, MK, and SF. 


\section{List of Figures}

555

556

557

558

559

560

561

562

563

564

565

566

567

568

569

570

571

572

573

574

575

576

577

578

579

580

6

67

70

72

73

74

76

Fig. 1 The 7-and 28-day compressive strength of the geopolymer concrete specimens.

Fig. 2 Factorial diagrams of the main parameters that affect the 7-day compressive strength of geopolymer mix under ambient curing condition.

Fig. 3 The significant of the main Parameters that affects the 7-day compressive strength of mixes.

Fig. 4 The effect of partial replacement of GGBFS with FA, MK, and SF on the setting time.

Fig. 5 The effect of partial replacement of GGBFS with FA, MK, and SF on the workability.

Fig. 6 The effect of partial replacement of GGBFS with FA, MK, and SF on the 7-day compressive strength.

8

669


581 Table 1

582 Chemical compositions (mass \%) for GGBS [29], FA [31], SF [29], and MK [32].

\begin{tabular}{lcccc}
\hline Component & GGBS & FA & SF & MK \\
\hline $\mathrm{SiO}_{2}$ & 32.40 & 62.2 & 85.76 & 52.21 \\
\hline $\mathrm{Al}_{2} \mathrm{O}_{3}$ & 14.96 & 27.5 & 1.89 & 44.08 \\
\hline $\mathrm{Fe}_{2} \mathrm{O}_{3}$ & 0.83 & 3.92 & 0.56 & - \\
\hline $\mathrm{CaO}$ & 40.70 & 2.27 & 0.92 & 1.69 \\
\hline $\mathrm{MgO}$ & 5.99 & 1.05 & 0.81 & - \\
\hline $\mathrm{K}_{2} \mathrm{O}$ & 0.29 & 1.24 & 0.86 & - \\
\hline $\mathrm{Na}_{2} \mathrm{O}$ & 0.42 & 0.52 & 0.74 & - \\
\hline $\mathrm{TiO}_{2}$ & 0.84 & 0.16 & - & 0.18 \\
\hline $\mathrm{P}_{2} \mathrm{O}_{5}$ & 0.38 & 0.30 & - & - \\
\hline $\mathrm{Mn}_{2} \mathrm{O}_{3}$ & 0.40 & 0.09 & - & - \\
\hline $\mathrm{SO}_{3}$ & 2.74 & - & 0.3 & - \\
\hline $\mathrm{LOI}$ & NA & - & 4.0 & - \\
\hline
\end{tabular}

583

LOI: Loss of ignition

584

585

586

587

588

589

590

591

592

593

594

595

596

597

598

599

600 
601 Table 2

602 Parameters and proportions used in the Taguchi experiment design.

\begin{tabular}{lccc}
\hline Parameters & Proportion 1 & Proportion 2 & Proportion 3 \\
\hline Binder content $\left(\mathrm{kg} / \mathrm{m}^{3}\right)$ & 400 & 450 & 500 \\
\hline Al/Binder & 0.35 & 0.45 & 0.55 \\
\hline SS/SH & 1.5 & 2.0 & 2.5 \\
\hline SH $(\mathrm{M})$ & 10 & 12 & 14
\end{tabular}

603

604

605

606

607

608

609

610

611

612

613

614

615

616

617

618

619

620

621

622

623

624

625

626 
Table 3

628 Parameters and values used in geopolymer concrete trial mixes.

\begin{tabular}{lcccc}
\hline Experiment series & Binder content $\left(\mathrm{kg} / \mathrm{m}^{3}\right)$ & Al/Binder & SS/SH & SH $(\mathrm{M})$ \\
\hline TM1 & 400 & 0.35 & 1.5 & 10 \\
\hline TM2 & 400 & 0.45 & 2 & 12 \\
\hline TM3 & 400 & 0.55 & 2.5 & 14 \\
\hline TM4 & 450 & 0.35 & 2 & 14 \\
\hline TM5 & 450 & 0.45 & 2.5 & 10 \\
\hline TM6 & 450 & 0.55 & 1.5 & 12 \\
\hline TM7 & 500 & 0.35 & 2.5 & 12 \\
\hline TM8 & 500 & 0.45 & 1.5 & 14 \\
\hline TM9 & 500 & 0.55 & 2 & 10
\end{tabular}

629

630

631

632

633

634

635

636

637

638

639

640

641

642

643

644

645

646 
647

648 Mix proportions of trial mixes.

\begin{tabular}{|c|c|c|c|c|c|c|c|c|c|}
\hline Mix & TM1 & TM2 & TM3 & TM4 & TM5 & TM6 & TM7 & TM8 & TM9 \\
\hline GGBS $\left(\mathrm{kg} / \mathrm{m}^{3}\right)$ & 400 & 400 & 400 & 450 & 450 & 450 & 500 & 500 & 500 \\
\hline $\mathrm{Al} / \mathrm{Bi}$ & 0.35 & 0.45 & 0.55 & 0.35 & 0.45 & 0.55 & 0.35 & 0.45 & 0.55 \\
\hline $\mathrm{SS} / \mathrm{SH}$ & 1.5 & 2 & 2.5 & 2 & 2.5 & 1.5 & 2.5 & 1.5 & 2 \\
\hline $\mathrm{SS}\left(\mathrm{kg} / \mathrm{m}^{3}\right)$ & 84 & 120 & 157 & 105 & 145 & 149 & 125 & 135 & 183 \\
\hline $\mathrm{SH}\left(\mathrm{kg} / \mathrm{m}^{3}\right)$ & 56 & 60 & 63 & 53 & 58 & 99 & 50 & 90 & 92 \\
\hline $\mathrm{SH}(\mathrm{M})$ & 10 & 12 & 14 & 14 & 10 & 12 & 12 & 14 & 10 \\
\hline $\begin{array}{l}\text { Superplasticizer } \\
\left(\mathrm{kg} / \mathrm{m}^{3}\right)\end{array}$ & 20 & 20 & 20 & 22.5 & 22.5 & 22.5 & 25 & 25 & 25 \\
\hline
\end{tabular}

$\begin{array}{llllllllll}\text { Water }\left(\mathrm{kg} / \mathrm{m}^{3}\right) & 48 & 48 & 48 & 54 & 54 & 54 & 60 & 60 & 60\end{array}$

\begin{tabular}{llllllllll}
\hline $\begin{array}{l}\text { Aggregate } \\
\left(\mathrm{kg} / \mathrm{m}^{3}\right)\end{array}$ & 1208 & 1182 & 1156 & 1161 & 1132 & 1102 & 1115 & 1082 & 1050
\end{tabular}

\begin{tabular}{llllllllll}
\hline $\mathrm{H}_{2} \mathrm{O} / \mathrm{Na}_{2} \mathrm{O}$ & 12.5 & 12.5 & 12.5 & 12.5 & 12.5 & 12.5 & 12.5 & 12.5 & 12.5
\end{tabular}


659

660 661

\begin{tabular}{ccc}
\hline & \multicolumn{2}{c}{ Compressive strength (MPa) } \\
\cline { 2 - 3 } Trial mix & 7 days & 28 days \\
\hline TM1 & 40.89 & 46.75 \\
\hline TM2 & 38.47 & 38.98 \\
\hline TM3 & 36.94 & 42.55 \\
\hline TM4 & 56.05 & 61.15 \\
\hline TM5 & 41.40 & 42.24 \\
\hline TM6 & 35.03 & 37.32 \\
\hline TM7 & 52.23 & 59.50 \\
\hline TM8 & 40.13 & 42.93 \\
\hline TM9 & 32.61 & 34.40
\end{tabular}

662

663

664

665

666

667

668

669

670

671

672

673

674 
675 Table 6

676 Percentage of participation and Optimum levels of the considered parameters on the 7-day

677 compressive strength.

\begin{tabular}{lcccc}
\hline Parameter & GGBFS Content & Al/Bi & SS/SH & SH \\
\hline Percentage of participation (\%) & 10.09 & 71.23 & 7.01 & 11.66 \\
\hline Optimum Level & $450\left(\mathrm{~kg} / \mathrm{m}^{3}\right)$ & 0.35 & 2.5 & $14(\mathrm{M})$
\end{tabular}

678

679

680

681

682

683

684

685

686

687

688

689

690

691

692

693

694

695

696

697

698 
Table 7

700 Changes in the compressive strength of geopolymer concrete for the partial replacement of

701 GGBFS with FA, MK, and SF.

\begin{tabular}{cccc}
\hline $\begin{array}{c}\text { Replacing } \\
\text { percentage }(\%)\end{array}$ & \multicolumn{3}{c}{ 7-day compressive strength (MPa) } \\
\cline { 2 - 4 } & FA & MK & SF \\
\hline 0 & 60.38 & 60.38 & 60.38 \\
\hline 10 & 58.55 & 40.03 & 42.16 \\
\hline 20 & 56.34 & 34.21 & 36.10 \\
\hline 30 & 49.20 & 28.14 & 32.12 \\
\hline 40 & 42.68 & & 30.41 \\
\hline 50 & 40.82 & 26.75 & 29.55 \\
\hline 60 & 35.41 & 25.78 & 28.98
\end{tabular}

702

703

704

705

706

707

708

709

710

711

712 


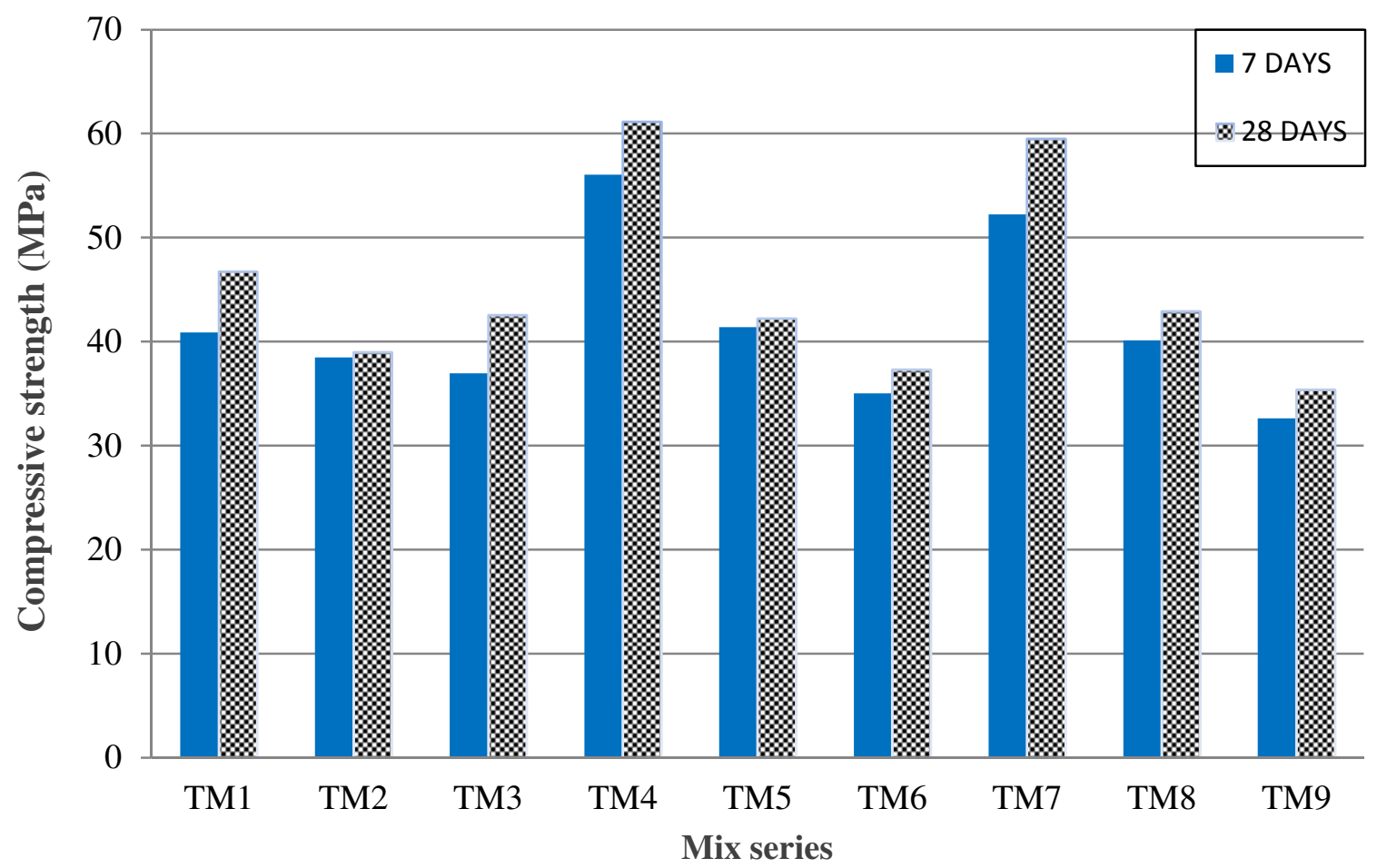

713

Fig. 1. The 7- and 28-day compressive strength of the geopolymer concrete specimens.

716

717

718

719

720

721

722

723

724 
725

726

727

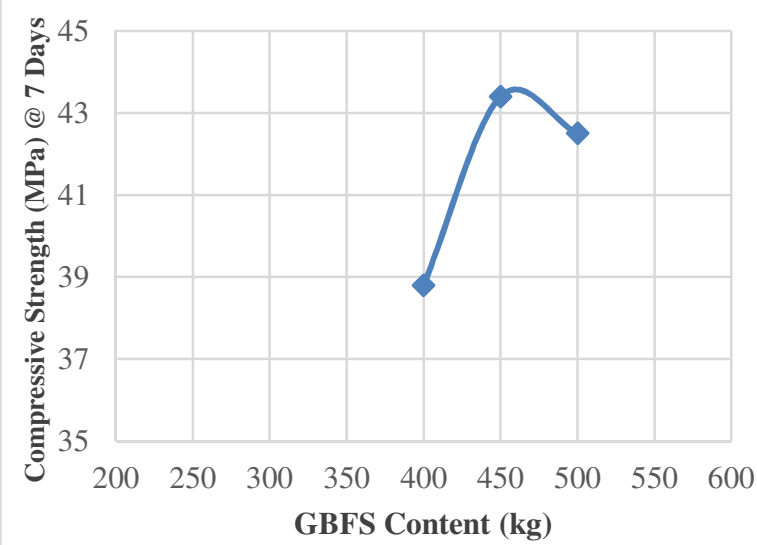

a) Binder content

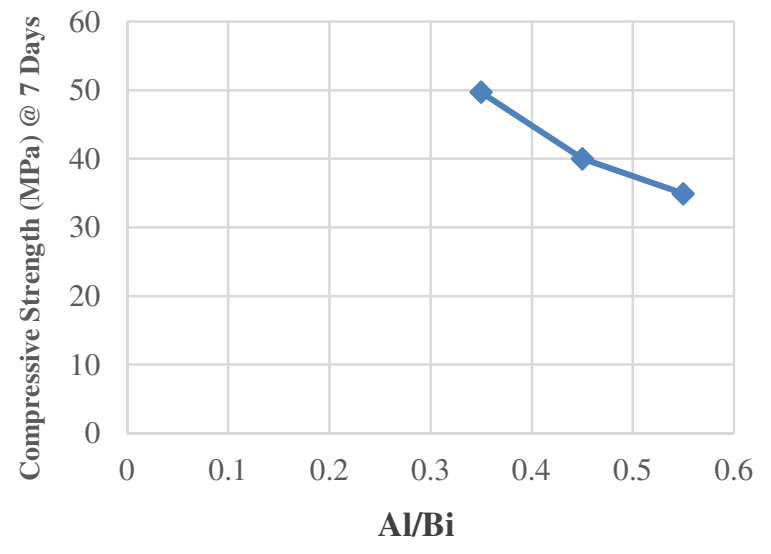

b) $\mathrm{Al} / \mathrm{Bi}$

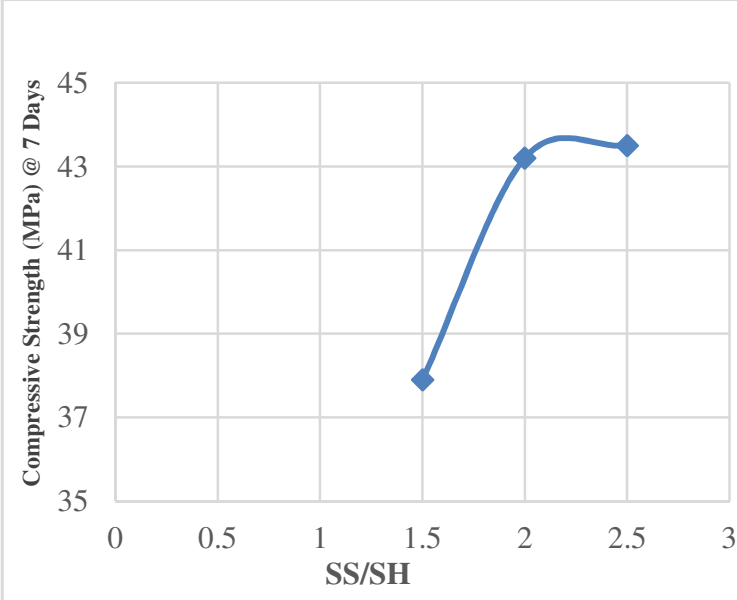

c) $\mathrm{SS} / \mathrm{SH}$

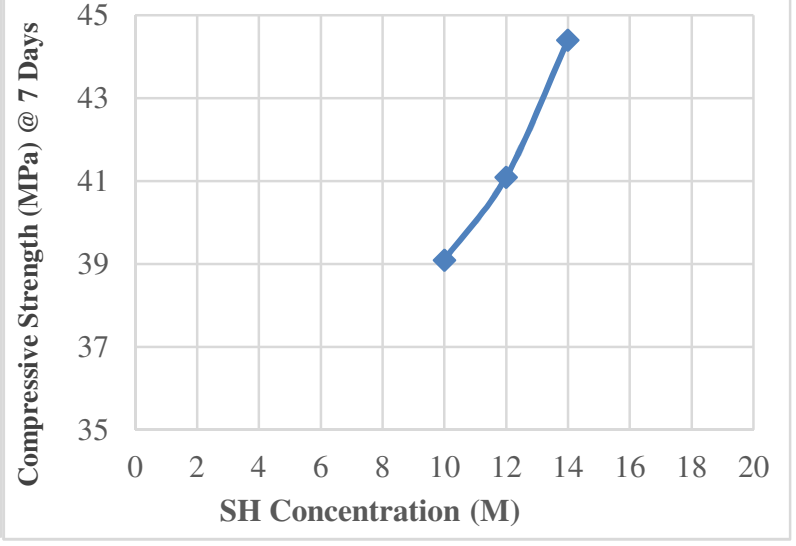

d) SH Concentration (M)

Fig. 2. Factorial diagrams of the main parameters that affect the 7-day compressive strength of geopolymer mix under ambient curing condition. 


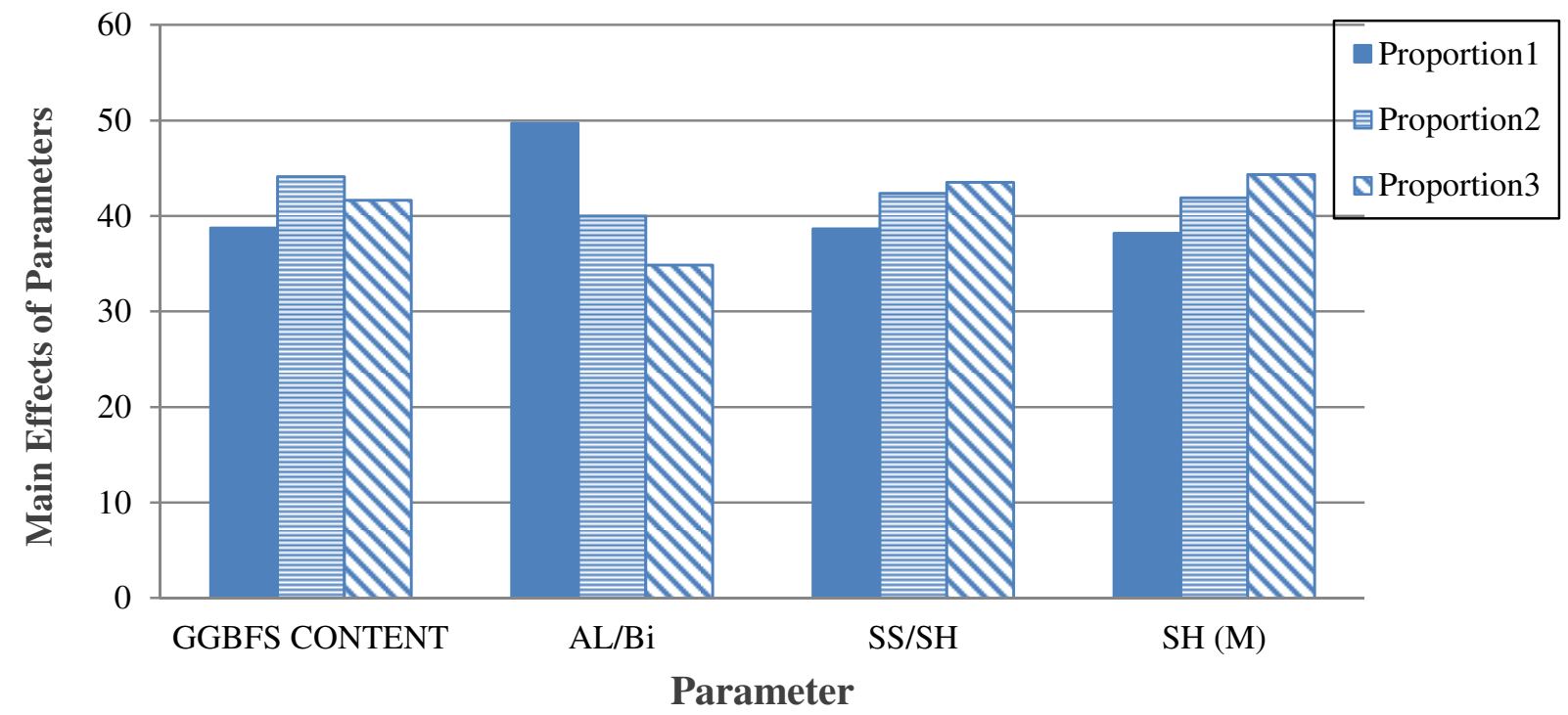

732

Fig. 3. The significant of the main parameters that affect the 7-day compressive strength of 734 mixes.

735

736

737

738

739

740

741

742

743

744

745

746

747

748

749 

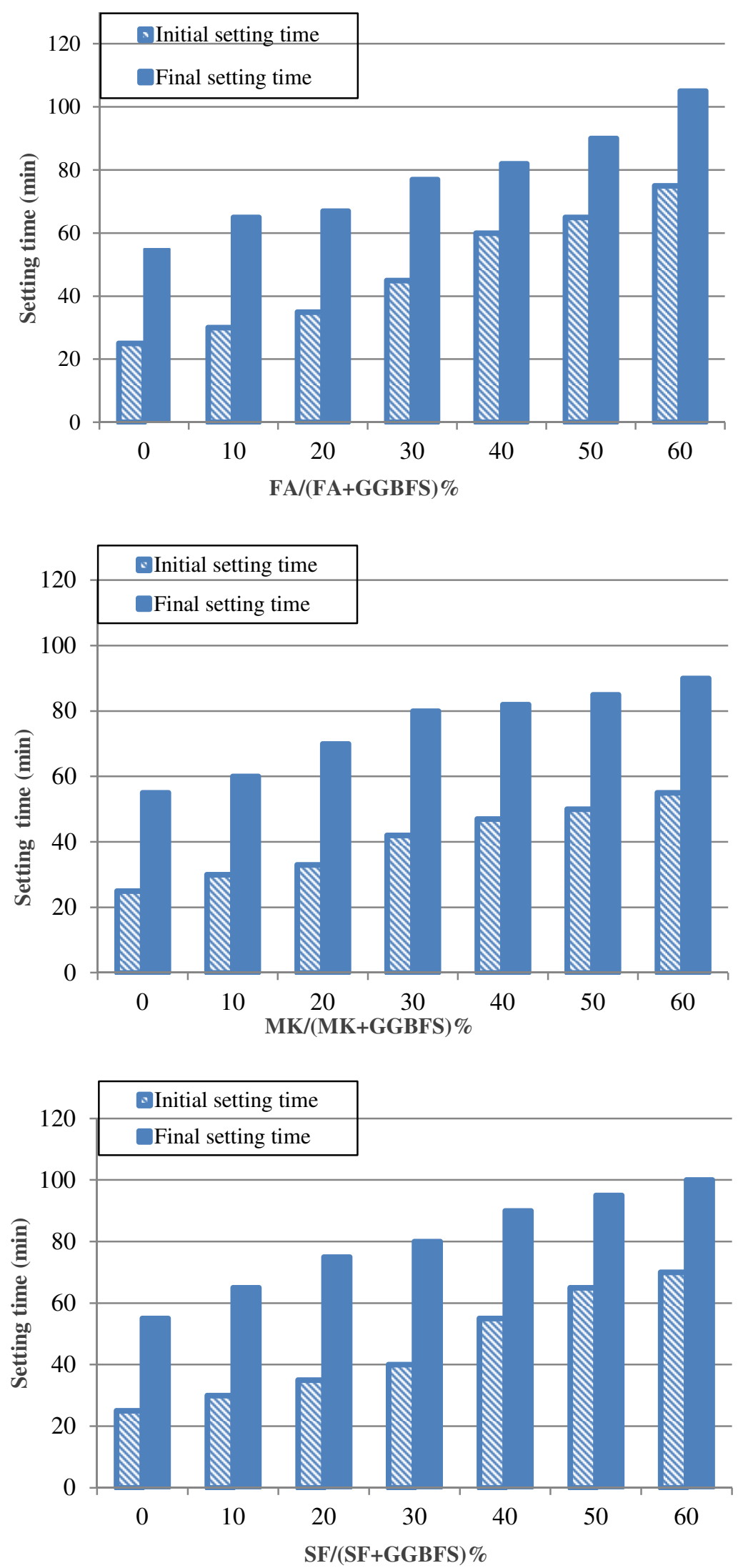


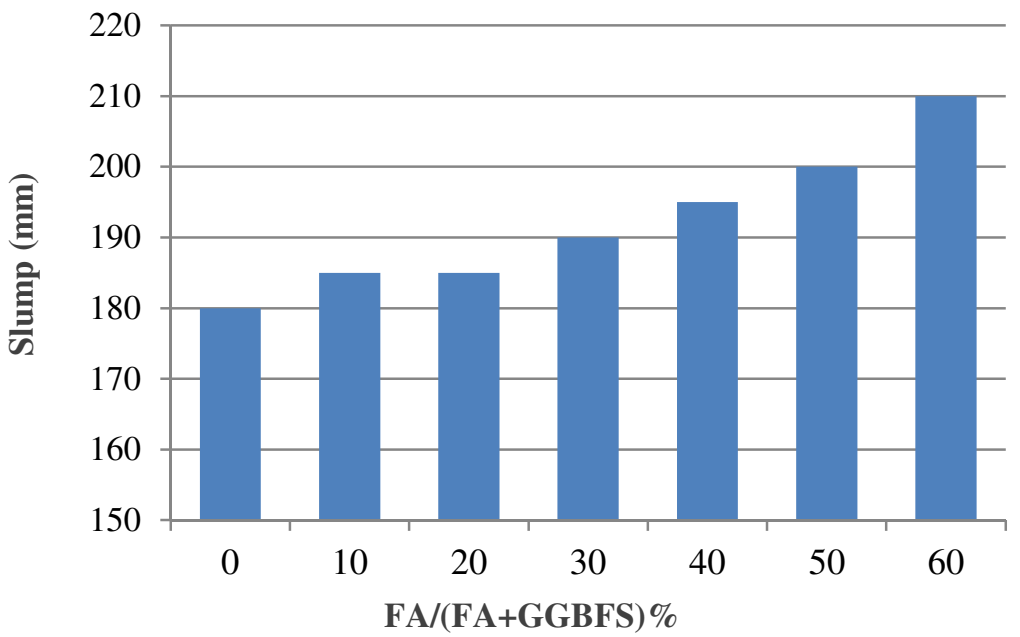

755
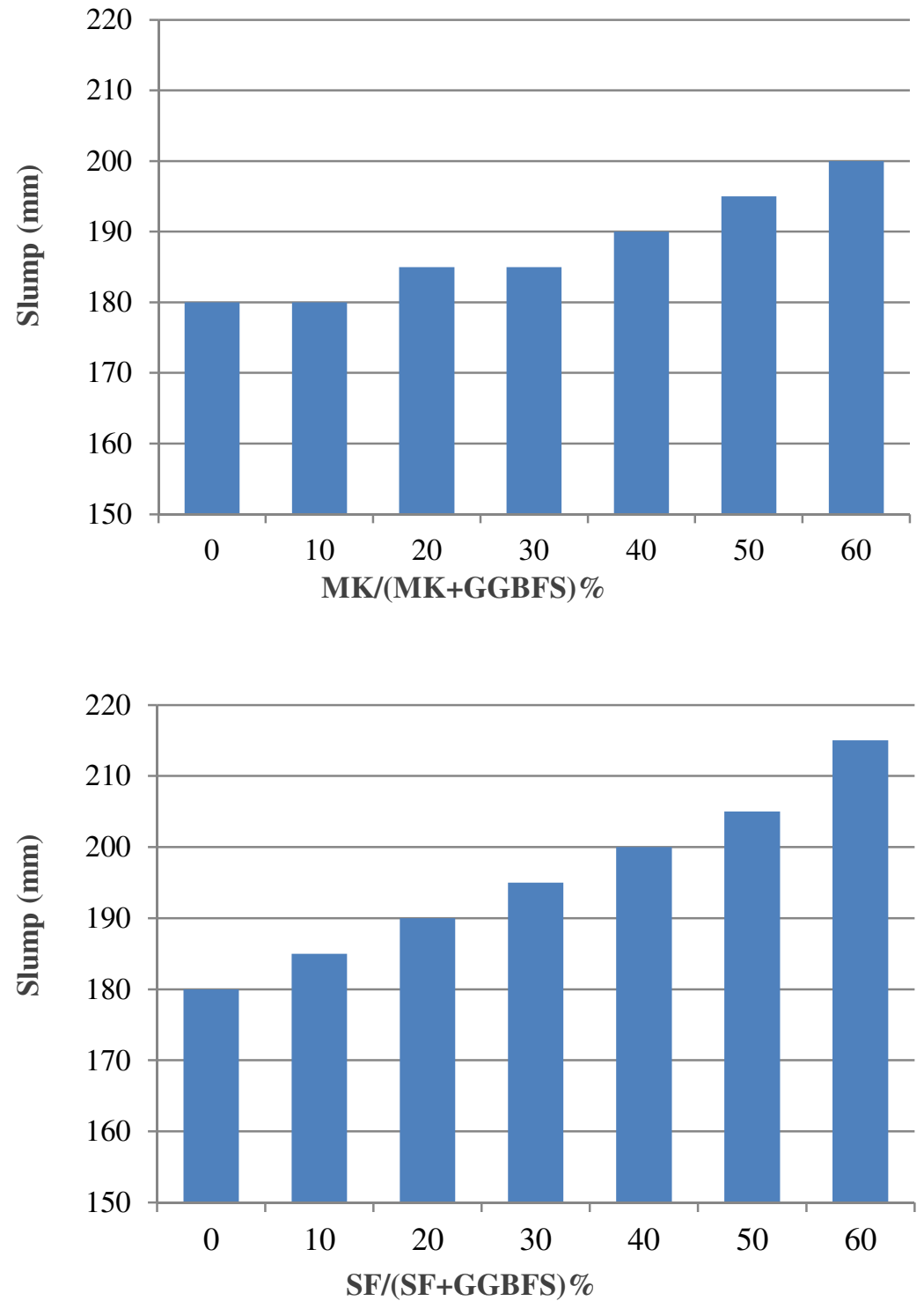

756

757 Fig. 5. The effect of partial replacement of GGBFS with FA, MK, and SF on the workability. 

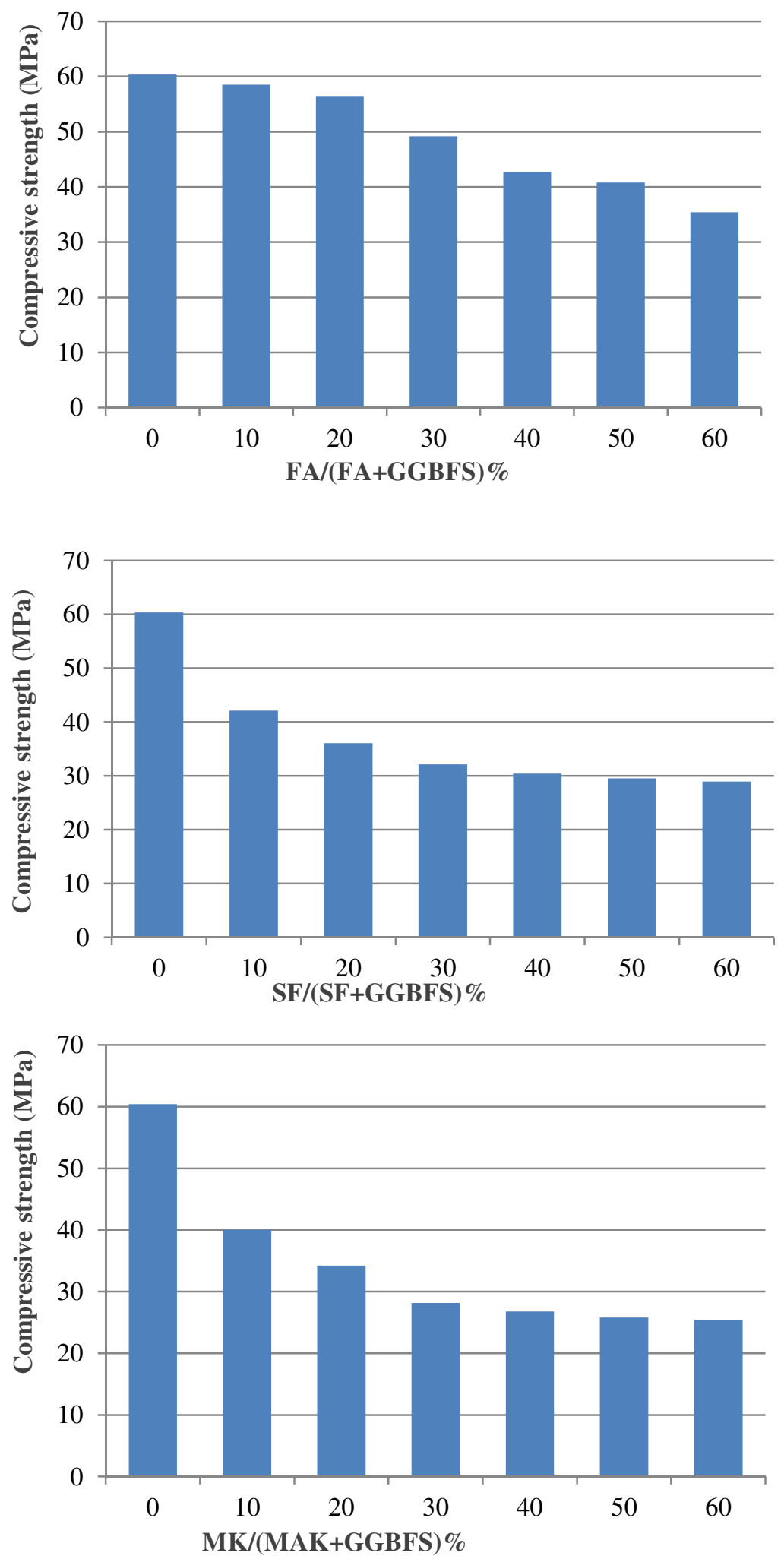

Fig. 6. The effect of partial replacement of GGBFS with FA, MK, and SF on the 7-day 